\title{
Drought impacts on vegetation in the pre- and post-fire events over Iberian Peninsula
}

\author{
C. M. Gouveia ${ }^{1,2}$, A. Bastos ${ }^{1}$, R. M. Trigo ${ }^{1,3}$, and C. C. DaCamara ${ }^{1}$ \\ ${ }^{1}$ IDL, Faculdade de Ciências, Universidade de Lisboa, Portugal \\ ${ }^{2}$ Escola Superior de Tecnologia, Instituto Politécnico de Setúbal, Setúbal, Portugal \\ ${ }^{3}$ Departamento de Engenharias, Universidade Lusófona, Lisboa, Portugal
}

Correspondence to: C. M. Gouveia (cmgouveia@fc.ul.pt)

Received: 29 February 2012 - Revised: 3 August 2012 - Accepted: 21 August 2012 - Published: 19 October 2012

\begin{abstract}
The present work aims to study the combined effect of drought and large wildfires in the Iberian Peninsula relying on remotely sensed data of vegetation dynamics and leaf moisture content, in particular monthly NDVI, NDWI and NDDI time series from 1999-2009, derived from VEGETATION dataset. The impact of the exceptional 2004/2005 drought on vegetation was assessed for vegetation recovering from the extraordinary fire season of 2003 and on the conditions that contributed to the onsetting of the fire season of 2005. Drought severity was estimated by the cumulative negative effect on photosynthetic activity (NDVI) and vegetation dryness (NDDI), with about $2 / 3$ of Iberian Peninsula presenting vegetative stress and low water availability conditions, in spring and early summer of 2005. Furthermore, NDDI has shown to be very useful to assess drought, since it combines information on vegetation and water conditions. Moreover, we show that besides looking at the inter-annual variability of NDVI and NDDI, it is useful to evaluate intraannual changes ( $\delta$ NDVI and $\delta$ NDDI), as indicators of change in vegetation greenness, allowing a detailed picture of the ability of the different land-cover types to resist to short-term dry conditions.
\end{abstract}

In order to assess drought impact on post-fire regeneration, recovery times were evaluated by a mono-parametric model based on NDVI data and values corresponding to drought months were set to no value. Drought has shown to delay recovery times for several months in all the selected scars from 2003.

The analysis of vegetation dynamics and fire selectivity in 2005 suggests that fires tended to occur in pixels presenting lower vegetative and water stress conditions during spring and early summer months. Additionally, pre-fire vegetation dynamics, in particular vegetation density and water availability during spring and early summer, has shown to influence significantly the levels of fire damage. These results stress the role of fuel availability in fire occurrence and impact on the Iberian Peninsula.

\section{Introduction}

Water availability is known to play a major role in vegetation dynamics in arid regions, namely in the dry prone areas of the Iberian Peninsula (Vicente-Serrano and Heredia-Laclaustra, 2004; Vicente-Serrano, 2006; Gouveia et al., 2008). Drought occurrence in the Iberian Peninsula (IP) is relatively frequent (Sousa et al., 2011), striking the region with apparent increasing frequency in the last two decades (1991/1992, 1994, 1998, 2002). Therefore, if the occurrence of yet another drought in 2004/2005 cannot be considered an unexpected event, its exceptional strength has made it one of the most severe droughts that has struck IP since the early 20th century (Garcia-Herrera et al., 2007), mostly affecting the southern sectors of both Iberian countries (Portugal and Spain). In particular, more than half of Portugal was under the effects of significant dry conditions for more than nine months (Gouveia et al., 2009), leading to major social and environmental impacts. Besides, this drought episode had a strong impact on Iberian ecosystems since it coincided with the period of higher photosynthetic activity (Gouveia et al., 2009) and may have increased tree mortality during 2005 and 2006 (Catry et al., 2010).

Mediterranean ecosystems have evolved along with wildfire disturbance, being well adapted to recover after fire 
(Naveh, 1975). However, due to the changes in fire regimes registered in recent decades, namely the increase of number and extent of fire events, wildfires have become a serious problem in land management over the Mediterranean (Pausas and Vallejo, 1999). Several authors have highlighted the importance of understanding wildfires as an ecological phenomenon characterized by the interaction of a number of factors, such as fire regime characteristics, climate conditions and the response of ecosystems to disturbance (Whelan, 1995; De Luís et al., 2001).

Pereira et al. (2005) have pointed out the existence of two main climatic factors controlling the extent of burnt area in Portugal: a relatively long dry period with absence of precipitation in late spring and early summer and the occurrence of very intense dry spells during days of extreme synoptic situations. The outstanding fire season of 2003, which coincided with a major heat wave that struck Europe (Trigo et al., 2005), has registered the highest extent of burnt area since 1980 with more than 425000 ha burned (JRC-EC, 2010) about $5 \%$ of the Portuguese mainland (Trigo et al., 2006). Following this exceptional fire season, the severe drought of 2004/2005 preceded another remarkable one, in 2005, corresponding to the second highest extent of burnt area in Portugal since 1980, with about 338000 ha burnt (JRC-EC, 2010; Pereira et al., 2011) and the highest extent of burned area in Spain since 1994, with more than 188000 ha burnt (JRC-EC, 2010), most of the events occurring in the adjacent northwestern Spanish Province of Galicia, adjacent to Portugal.

Remote sensing has been widely used to study Mediterranean ecosystems, namely to evaluate the climate impact on vegetation dynamics (Vicente-Serrano and HerediaLaclaustra, 2004; Julien et al., 2006; Gouveia et al., 2008), to monitor post-fire vegetation recovery (Wittenberg et al., 2007; Röder et al., 2008; Malkinson et al., 2011) as well as to assess fire risk (Chuvieco et al., 2010) and burn severity (De Santis and Chuvieco, 2007; Fox et al., 2008).

Several algorithms that aim at discriminating green vegetation are based on so-called Vegetation Indices (VIs), which combine the measured radiances reflected by land surface in different spectral bands of the atmospheric window. The Normalised Difference Vegetation Index (NDVI) relies on Red and Near Infra-Red (NIR) reflectances and essentially provides information about leaf chlorophyll levels and vegetation density. This index has been shown to be particularly useful to analyse post-fire vegetation recovery (e.g. DíazDelgado et al., 1998; Díaz-Delgado and Pons, 2001; Fox et al., 2008; Gouveia et al., 2010; Bastos et al., 2011) and to monitor vegetation dynamics during the extreme waterstress conditions such as those observed in Portugal during the 2004/05 drought (Gouveia et al., 2009). Several authors have nevertheless shown the better suitability of the Normalised Difference Water Index (NDWI), an index based on MODIS NIR $(0.86 \mu \mathrm{m})$ and Short-Wave Infra-Red (SWIR $-1.24 \mu \mathrm{m}$ ) channels, to monitor leaf water content (Gao, 1996; Ceccato et al., 2001; Hao and Qu, 2007), the effects of drought on the canopy (Gu et al., 2007; Anderson et al., 2010) and fuel moisture content (Maki et al., 2004). Gond et al. (2004) have in turn adapted the NDWI index proposed by Gao (1996) to SPOT-VEGETATION instrument datasets, using NIR $(0.84 \mu \mathrm{m})$ and MIR $(1.64 \mu \mathrm{m})$ channels (Hagolle et al., 2005). In order to improve sensitivity to drought severity, $\mathrm{Gu}$ et al. (2007) proposed an index that combines information on vegetation activity and water content, the so called Normalised Difference Drought Index (NDDI). This index, which is simply obtained through the normalised difference between NDVI and NDWI, has shown to have a better response to summer drought conditions.

Gouveia et al. (2010) have proposed a methodology to estimate the time required for post-fire vegetation recovery by fitting a mono-parametric model to observed NDVI data from SPOT-VEGETATION instrument. This model was upgraded and successfully applied to monitor several large burnt scars in Portugal that resulted from the fire seasons of 2003, 2004 and 2005 (Bastos et al., 2011). One should however recognise that the use of post-fire recovery algorithms based solely on NDVI is not easily implemented in other areas with a Mediterranean type of climate. Including the above mentioned water related indices (NDWI and NDDI) in the analysis of drought would allow extending its applicability to other areas outside Portugal, namely to those prone to drought events. Such inclusion would also provide a sounder physical basis to the mono-parametric model of post fire vegetation recovery.

The aim of the present work is to assess the impact of water scarcity conditions which were observed during the 2004/2005 drought in the IP on pre-fire vegetation dynamics as well as in post-fire vegetation recovery. As specific goals, the work intends

i. to assess the impact of drought on vegetation dynamics during the hydrological year of 2005 using NDVI, NDWI and NDDI indices;

ii. to estimate drought impact on times of post-fire vegetation recovery for selected scars with respect to the 2003 fire season;

iii. to evaluate drought impact on vegetation dynamics for the months preceding the 2005 fire season. In particular to (1) compare drought effects on different land-cover types, over burned and unburned pixels; (2) identify differences between areas affected by drought and areas not severely affected; and (3) assess the impacts of prefire conditions on fire damage and recovery times.

Throughout this work one should however keep in mind the very different nature of the impact of the outstanding 2004/2005 drought on the 2003 and 2005 large fire scars. In the case of the scars from 2003, the study focuses on the way the drought affects the recovery process almost $2 \mathrm{yr}$ after the fire events. On the contrary, relatively to the 2005 scars, the 
analysis respects to the impact of drought on pre-fire vegetation behaviour for different land-cover types.

\section{Data and methods}

\subsection{Vegetation dynamics and drought monitoring}

In the present work, the assessment of vegetation dynamics relies on corrected NDVI datasets as acquired from VEGETATION instrument on board of SPOT4 and SPOT5 satellites and covering the whole IP. Since 1998, the VEGETATION instrument has been providing high quality global monitoring on a daily basis of land-cover dynamics, in the Blue (B0, $460 \mathrm{~nm})$, Red (B2, $670 \mathrm{~nm})$, Near Infra-Red (B3, $840 \mathrm{~nm}$ ) and Medium Infra-Red (MIR, $1640 \mathrm{~nm}$ ) spectral bands (Hagolle et al., 2005).

Radiometric and NDVI data were extracted from the S10 products of the VITO database (http://free.vgt.vito.be), which provides a 10-day synthesis of the daily products, based on the maximum-value composite method (MVC). This method consists in selecting, for each pixel, the highest value of NDVI for each 10-day period, thus allowing to remove most of the cloudy pixels (Holben, 1986), provided MVC data are already corrected for atmospheric effects, using a modified version of the Simple Method for the Atmospheric Correction (SMAC) code that accounts for absorption and scattering processes (Rahman and Dedieu, 1994). Geometric and radiometric corrections are also performed, according to the procedures described in Maisongrande et al. (2004). S10 products are organised on a regular latitudelongitude grid, using the WSG84 ellipsoid, at the resolution of $0.008928^{\circ}$ (approximately $1 \mathrm{~km}^{2}$ over the Equator). B3, MIR and NDVI data for the Iberian Peninsula were selected for a region extending from $36^{\circ} \mathrm{N}$ to $44^{\circ} \mathrm{N}$ and from $9.5^{\circ} \mathrm{W}$ to $3.5^{\circ} \mathrm{E}$ within a period ranging from September 1998 to August 2009.

In order to generate a continuous European vegetation phenology dataset at 10 -day temporal and $0.1^{\circ}$ spatial resolution, each annual time series of MVC-NDVI was analysed and corrected following the procedure applied by Stöckli and Vidale (2004) to the Pathfinder NDVI data. This procedure comprises a spatial interpolation to replace processing artefacts and no-data values in the dataset and the adjustment of NDVI time series by using a temporal interpolation that relies on a weighted second-order Fourier analysis as described by Sellers et al. (1992) and Los (1998), in which different weighting functions are assigned to vegetation with a continuous transition between growing and non-growing period, such as evergreen, and between dormant and active periods for vegetation with a marked vegetative cycle. A full description of the procedure may be found in Gouveia et al. (2009).

NDWI is defined according to Gond et al. (2004) as

$\mathrm{NDWI}=\frac{\rho_{\mathrm{NIR}}-\rho_{\mathrm{MIR}}}{\rho_{\mathrm{NIR}}+\rho_{\mathrm{MIR}}}$.
Following Eq. (1), NDWI data were computed using B3 and MIR data. The corrections applied to the NDVI series described above were also performed on NDWI values in order to replace processing artefacts and no-data values in the dataset. Since NDWI values also present a seasonal cycle $(\mathrm{Gu}$ et al., 2007), a temporal interpolation based on a second order Fourier analysis was performed, similar to the one applied on NDVI values.

NDDI values were simply computed according to the definition proposed by Gu et al. (2007):

$\mathrm{NDDI}=\frac{\mathrm{NDVI}-\mathrm{NDWI}}{\mathrm{NDVI}+\mathrm{NDWI}}$

A comparison between the three indexes (NDVI, NDWI and NDDI) and an assessment of the performance of NDDI as a drought indicator for grassland may be also found in $\mathrm{Gu}$ et al. (2007).

Information about land-cover over the Iberian Peninsula was based on Global Land Cover 2000 (GLC2000) provided by the Global Environment Monitoring Unit of the European Commission Joint Research Centre (http://bioval.jrc.ec. europa.eu). GLC2000 makes use of a dataset of 14 months of pre-processed daily global data acquired by the VEGETATION instrument on board the SPOT 4 satellite. GLC2000 data are provided at $1 \mathrm{~km}$ spatial resolution and information is stratified into 22 classes of land-cover.

\subsection{Burnt areas and vegetation recovery}

Gouveia et al. (2010) proposed a simple procedure to detect very large burnt scars from 2003 in Portugal, based on a K-means cluster analysis (MacQueen, 1967; Hartigan and Wong, 1979) of monthly MVC-NDVI anomalies performed over each hydrological year. Hydrological year is defined as the period spanning from September of the previous year to August of the considered year. The same procedure has also shown to provide satisfactory results in mapping burnt scars from 2004 and 2005 in Portugal, subject to the condition that pixels corresponding to burnt scars from previous seasons were removed (Bastos et al., 2011).

Since the method is based on unsupervised clustering of pixels with similar phenology, its application to a much broader area such as the entire IP must be performed cautiously. In fact, this region comprises a large diversity of ecosystems ranging from dense forests in the North to arid regions in the South that may introduce large variability on the analysis of the anomaly over any hydrological year. A preliminary cluster analysis of annual NDVI values over the 11 -yr period was accordingly performed in order to define four eco-regions characterized by similar phenology. Based on information provided by GLC2000, the four eco-regions were associated with (1) deciduous and evergreen forests; (2) forests and shrubland; (3) cultivated and managed areas and (4) sparse vegetation and bare soils. Since this work focuses on wildfires in forests and shrubs, only eco-regions 1 


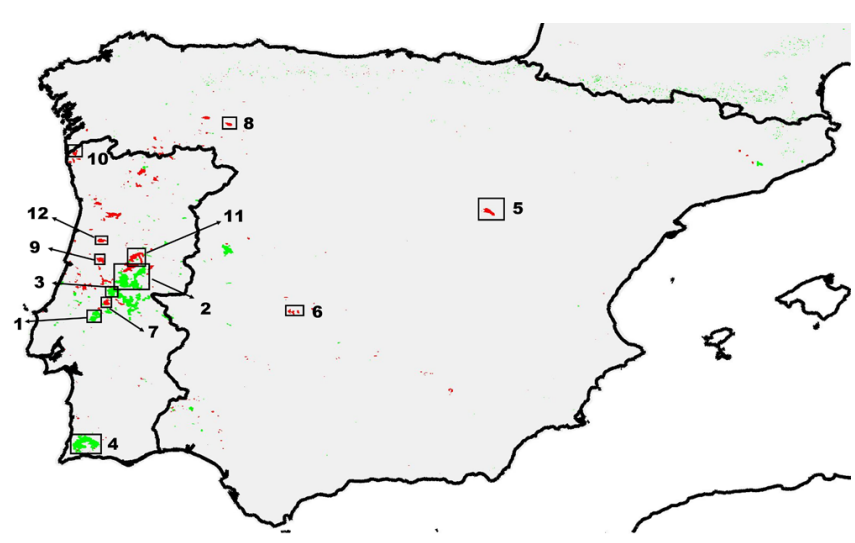

Fig. 1. Burned areas in the Iberian Peninsula for 2003 (green) and for 2005 (blue) fire seasons. Selected areas and respective nomenclature are indicated by rectangular boxes and numbers for 2003 (green areas 1 to 4 ) and for 2005 (red areas 5 to 12).

and 2 were retained for large burnt scar identification as derived from the procedure developed by Gouveia et al. (2010) with the upgrades and corrections introduced by Bastos et al. (2011). Results obtained for the two fire seasons (Fig. 1) were then compared with corresponding data from the global VGT burnt area (GBA) product available for the 2000-2007 period (Tansey et al., 2008). As expected, pixels classified as burned clearly matched the burned scars of summers of 2003 and 2005 obtained from GBA for forest and shrubland, after discarding the burned areas of the previous years (figure not shown).

Finally, a set of 12 burnt scars from 2003 and 2005 fire seasons were selected, covering different geographical locations over IP (boxes on Fig. 1). Burned areas 1 to 4 (hereafter referred to as A1 to A4 and represented in green in Fig. 1) correspond to the 2003 fire season, whereas areas 5 to 12 (hereafter referred to as A5 to A12 and represented in red in Fig. 1) correspond to the 2005 fire season.

\section{Drought assessment}

As shown in previous works, the hydrological year of 2004/2005 was characterized by an exceptional drought over IP with less than $40 \%$ of the climatological precipitation being registered in the southern sectors (Garcia-Herrera et al., 2007). According to Gouveia et al. (2009), roughly $65 \%$ of the area of Continental Portugal registered monthly anomalies of NDVI below -0.025 for 9 or more months, mainly affecting areas with non irrigated crops. These effects were enhanced by a previous "minor" drought that had been occurring since the winter months of 2004, when the precipitation for all months from February to June (excepting March) stayed below the 30th percentile, leading to a continuous decrease of soil moisture since the beginning of 2004 until the end of spring 2005 (Garcia-Herrera et al., 2007).
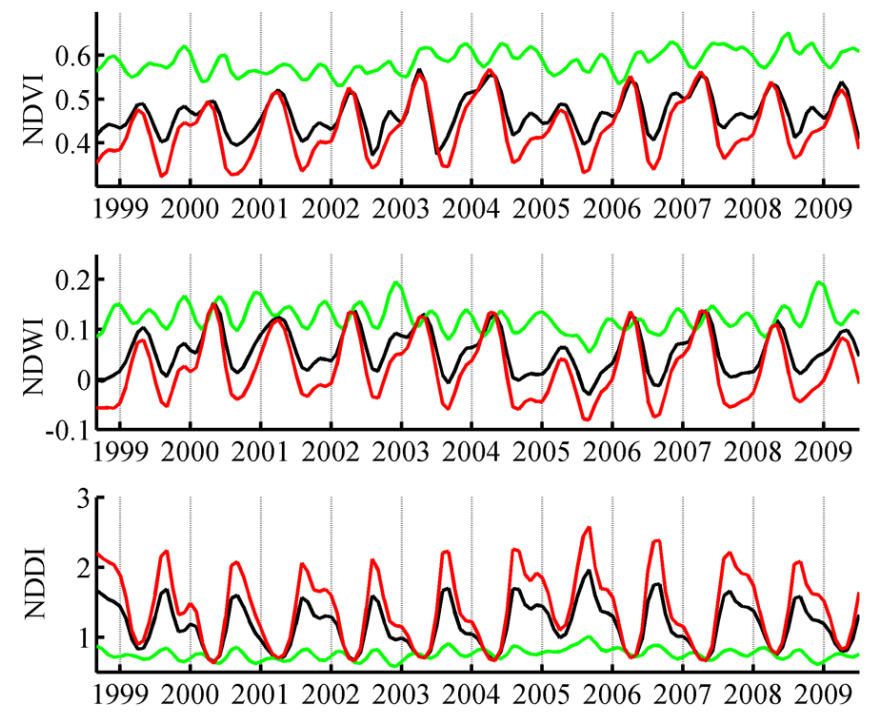

Fig. 2. Monthly time series (1999-2009) of NDVI (top panel), NDWI (central panel) and NDDI (lower bottom panel) averaged over Iberian Peninsula for all pixels (black line), for pixels of non-irrigated arable land (red line) and for pixels of needle-leaved forests (green line). Black arrows indicate the drought episode of 2005. Vertical dotted lines identify the month of January

\subsection{Drought impact on vegetation behaviour}

The NDVI time series averaged over the IP as well as for two different land-cover types are presented in Fig. 2 (top panel). Arable land and needle leaved forests reveal distinct phenologies, the latter presenting lower intra-annual variation, as expected. On the other hand, arable land presents a marked vegetative cycle. The effects of droughts on plant phenology (NDVI, top panel) and moisture content (NDWI, middle panel) are visible, especially for the years of 1999 and 2005 , both characterised by prolonged dry periods. However, the effect of drought in 2005 over needle-leaved forests is more evident in NDDI, which increased continuously until summer (Fig. 2, lower panel). This feature, is worth emphasizing since it translates into the ability of NDDI to assess drought events during summer making it more adequate to monitor vegetation dryness than NDVI or NDWI alone. It may be noted that the increase in NDDI is less pronounced in the case of the 1999 event but this may be due to the fact that the scarcity of water in the soil only remained until spring, as opposed to the 2005 event where it persisted until summer (Gouveia et al., 2009).

The temporal evolution of the anomalous patterns of NDVI, NDWI and NDDI during the hydrological year of 2005 (Fig. 3) provides additional insight on the impact of this strong drought episode on the vegetation dynamics over the whole IP. Negative values of both NDVI and NDWI anomalies were registered covering a large fraction of the IP vegetation (mostly in the south and central sectors), which increased systematically from December 2004 until June 2005. 

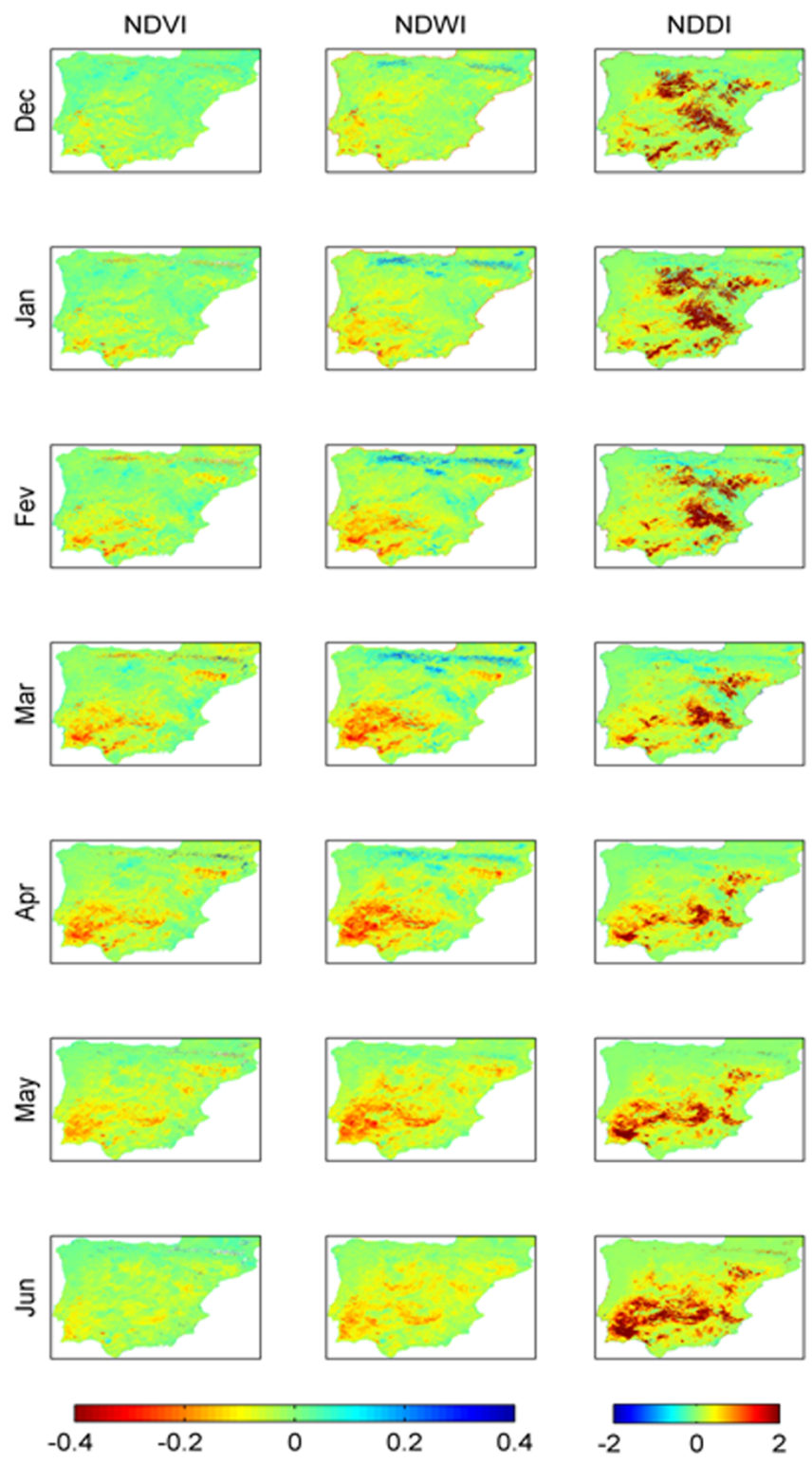

Fig. 3. Monthly NDVI (left panel), NDWI (central panel) and NDDI (right panel) anomalies from December 2004 to June 2005, with respect to the hydrological year of 2004/2005.

From April until June, roughly two-thirds of the IP vegetation was under vegetative stress and presented very low moisture content. Accordingly, very high positive values of NDDI anomaly were observed over a large extent of land, especially over Eastern Iberia in winter and Southern Iberia during summer. It should be noted that the low water content in the vegetation detected in winter months (predominantly in the eastern sector of IP) results from the dry conditions that were registered in that area throughout 2004 (Levinson, 2005).

Following Gouveia et al. (2009), the duration of vegetative stress conditions for each pixel was evaluated by computing

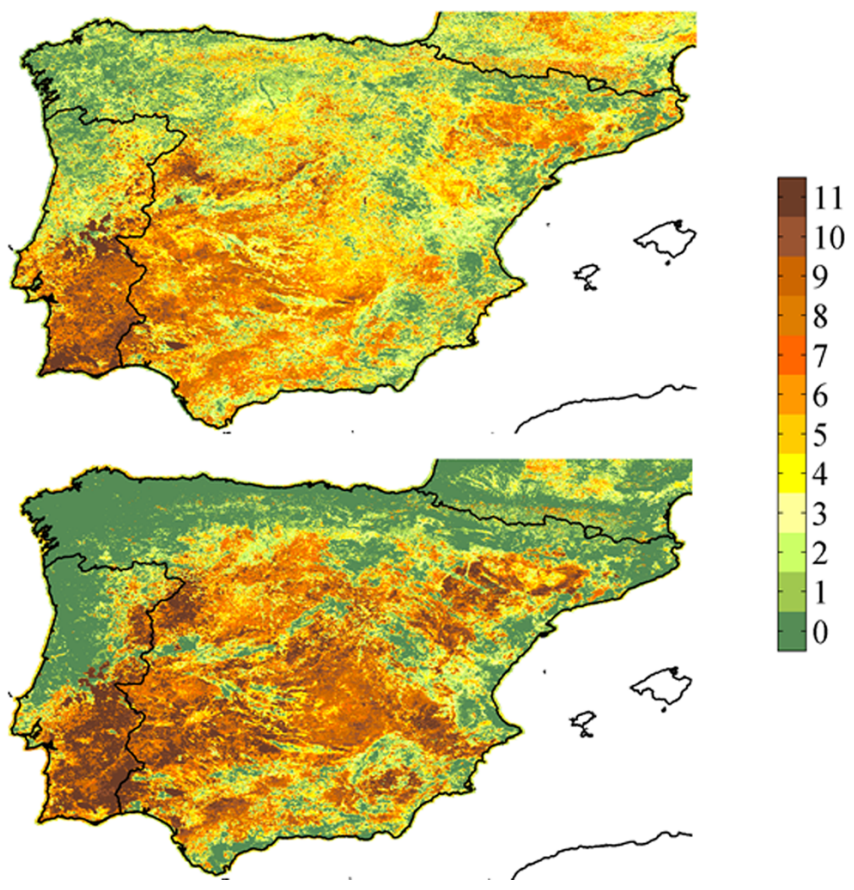

Fig. 4. Number of months between September 2004 and July 2005 characterised by (a) NDVI anomaly values below -0.025 (top); and (b) NDDI anomaly values above 0.25 (bottom).

the number of months presenting anomalies of NDVI of -0.025 below the corresponding median values, evaluated over the 11-yr period (Fig. 4, top panel), within the period ranging from September 2004 to July 2005 (i.e. before the occurrence of the larger fires). The same procedure was applied to NDDI anomaly fields (Fig. 4, bottom panel) using a positive threshold of 0.25 above median values over the 11 -yr period. NDVI anomalies essentially provide information about vegetation greenness deficits, i.e. vegetative stress, whereas NDDI anomalies indicate water deficits on live vegetation.

Even though both maps appear dominated by relatively similar patterns, different features of drought effects may be uncovered over IP. In general, most regions where vegetation has been under vegetative stress for several months also present a long period with very low moisture content. However, there are other regions, namely the Atlantic coastal ones between central Portugal and the Pyrenees, where despite presenting several months of vegetative stress, no evident effects on water availability may be observed. In fact, while about $27 \%$ of IP presented negative values of NDVI anomaly for six or more months, similar water-stress conditions, as those observed using NDDI anomalies, were monitored around $32 \%$ of the territory. These results indicate that NDDI is more sensitive to capture the effect of drought on vegetation activity, since it combines information on both photosynthetic activity and water availability. 

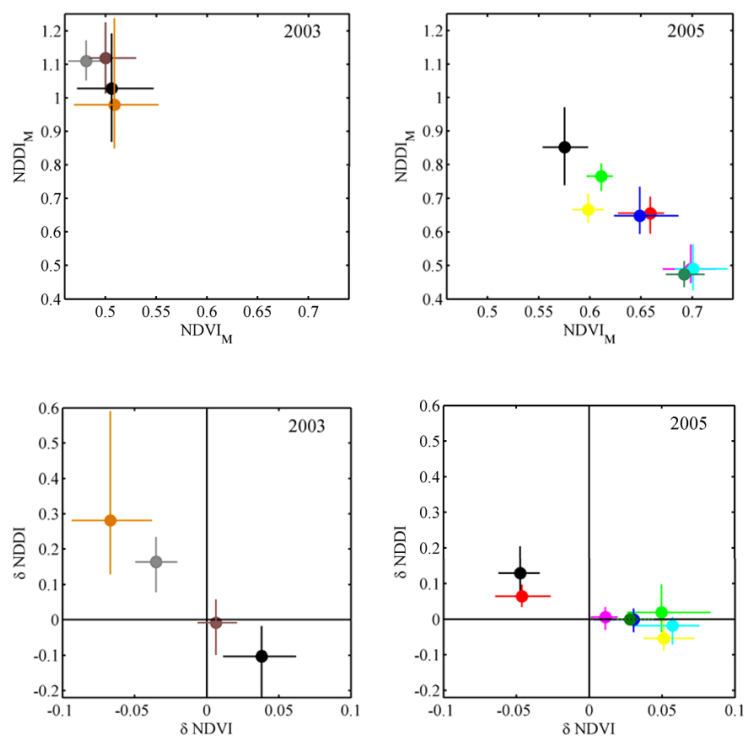

Fig. 5. Dispersion diagrams of centroids corresponding to the pairs $\mathrm{NDVI}_{\mathrm{M}}, \mathrm{NDDI}_{\mathrm{M}}$ (top panel) and $\delta \mathrm{NDVI}, \delta \mathrm{NDDI}$ (bottom panel) corresponding to the period from February to July 2005, for the area surrounding burnt scars of 2003 (left panel) and for the burnt scars of 2005 (right panel) fire seasons. Coordinates of the centroids are identified by filled circles in the dispersion diagrams, whereas horizontal and vertical bars indicate the interquartile ranges. Colours indicate selected scars of 2003: A1 (grey), A2 (black), A3 (brown), A4 (orange); and those of 2005: A5 (light green), A6 (black), A7 (red), A8 (yellow), A9 (magenta), A10 (cyan), A11 (blue), A12 (dark green).

It is worth noting that some pixels presenting 11 months of negative NDVI (positive NDDI) anomalies correspond to burnt scars from 2003 and 2004, being associated with vegetation that had not yet recovered. Selected burnt scars from 2003 and 2005 (those boxed in Fig. 1) are located in regions with dissimilar behaviours and diversely affected by drought, having been chosen because of the diversity of their locations. In particular, boxes A5, A6 and A7 are close to areas significantly affected by drought, whereas boxes A8 and A10 are located over sectors that were not particularly affected. Finally, the different role played by the 2004/2005 drought on the 2003 and 2005 scars may be appreciated. Whereas in relation to the 2003 scars, drought can only influence the recovery process observed roughly $2 \mathrm{yr}$ after the fire event, in the case of the 2005 scars drought is bound to influence the onsetting of the 2005 fire season (as well as the recovery process afterwards).

In order to evaluate the average vegetation activity and water conditions during late winter/spring and early summer months (from February to June), the corresponding mean values of NDVI and NDDI (hereafter denoted $\mathrm{NDVI}_{\mathrm{M}}$ and $\mathrm{NDDI}_{\mathrm{M}}$, respectively) were computed. For each burned area (Fig. 5, top panels), dispersion diagrams of centroids of pairs $\left\{\mathrm{NDVI}_{\mathrm{M}}, \mathrm{NDDI}_{\mathrm{M}}\right\}$ were then computed with the aim of estimating the intensity, duration and corresponding effect of drought on vegetation and, therefore, assessing the impact of dry conditions on the recovery process. In the case of 2005 burned areas (Fig. 5, right top panel), the computation was naturally performed over the pixels inside the respective scars, whereas in the case of 2003 (Fig. 5, right left panel), the procedure was applied to the area surrounding the scars. While $\mathrm{NDVI}_{M}$ provides information about vegetation density during those months, $\mathrm{NDDI}_{\mathrm{M}}$ gives information about corresponding dryness. High values of $\mathrm{NDDI}_{\mathrm{M}}$ indicate dry areas during the months preceding summer and low values correspond to areas with higher moisture content during those months. On the other hand, a high value of $\mathrm{NDVI}_{\mathrm{M}}$ indicates a higher than average value of green vegetation density while low values correspond to sparsely vegetated areas. Vegetation in the area surrounding the burn scars of the 2003 fire season (Fig. 5, left top panel) presents higher values of $\mathrm{NDDI}_{M}$ and lower values of $\mathrm{NDVI}_{\mathrm{M}}$. In this case, the highest level of dryness and the lowest of green vegetation $\left(\mathrm{NDVI}_{\mathrm{M}}\right)$ are observed for A1 and A3, whereas A4 presents slightly lower values of $\mathrm{NDDI}_{\mathrm{M}}$. However, $\mathrm{NDDI}_{\mathrm{M}}$ values obtained for all the 2005 burn scars (Fig. 5, right top panel) are lower than the values for the surrounding area of the burn scars of 2003, while the corresponding values of $\mathrm{NDVI}_{\mathrm{M}}$ are significantly higher. This implies that vegetation over the 2005 burnt scars corresponds to a distinct setting with higher vegetation density (higher biomass) and higher leaf moisture. In fact, A5 and A6 present a higher level of dryness and lower density of green vegetation (less but driest biomass) while A9, A10 and A12 correspond to higher levels of moisture content and higher density of green vegetation (more wet biomass).

Additionally, and in order to assess changes, in photosynthetic activity and in leaf moisture content, occurring between late winter and spring (February-May) and early summer (June-July), an analysis was performed to the differences of both NDVI and NDDI between summer and late winter, which are defined as follows:

$$
\begin{aligned}
& \delta \mathrm{NDVI}=\mathrm{NDVI}_{\mathrm{JJ}}-\mathrm{NDVI}_{\mathrm{FMAM}} \\
& \delta \mathrm{NDDI}=\mathrm{NDDI}_{\mathrm{JJ}}-\mathrm{NDDI}_{\mathrm{FMAM}} .
\end{aligned}
$$

Values of $\delta$ NDVI and $\delta$ NDDI were accordingly computed for each pixel surrounding the burn scars A1 to A4 with regard to the fire season of 2003 (Fig. 5, left bottom panel) and over burnt scars A5 to A12 of 2005 (Fig. 5, right bottom panel). A negative value of $\delta$ NDVI implies a strong decrease of green vegetation (i.e. either less green or less dense vegetation) from late winter to early summer, whereas a negative value of $\delta$ NDDI points to an increase of leaf moisture from late winter to early summer.

Centroids corresponding to the pairs $\{\delta$ NDVI, $\delta N D D I\}$ respecting to each burnt scar reveal marked differences on the respective behaviour, especially for those more severely affected by the 2004/2005 drought. Centroids presenting low 
negative values of $\delta$ NDVI and positive values of $\delta$ NDDI (2nd quadrant) correspond to areas registering a decrease in vegetation density and in moisture content (Fig. 5 bottom, left panel).

In the case of A4 and A1, green vegetation markedly decreased in density and dried out from winter to summer, while vegetation became denser and moister for A2. Finally, burnt area $\mathrm{A} 3$ does not reveal a marked change from late winter to early summer, but presents the highest value of $\mathrm{NDDI}_{\mathrm{M}}$, an indication that this burnt scar was under particular intense dry conditions over the entire period from February to June. On the other hand, vegetation in A4 presents the lowest level of dryness, i.e. the lowest $\mathrm{NDDI}_{\mathrm{M}}$ over the period from February to June (Fig. 5 top, left panel). The relatively lower level of dryness of A4 could be related with eucalyptus being the predominant vegetation type which is particularly adapted to drought conditions.

In the case of 2005, only A6 and A7 present high $\delta$ NDDI and negative $\delta$ NDVI values, which correspond to an evolution towards a less green and drier vegetation however, as explained above, A7 does not present a marked dryness level (Fig. 5 top right panel). Despite presenting a distinct behaviour from the other two cases, A5 is considered to have been affected by drought since vegetation maintained very high values of $\mathrm{NDDI}_{\mathrm{M}}$ throughout the period preceding summer (Fig. 5 top right panel). The positive $\delta$ NDVI values are worth being noted since they may be associated with the phenology of vegetation in this scar, characterised by a peak of activity in summer. The corresponding $\delta$ NDDI values simply indicate that very low moisture conditions were observed mainly during spring and not summer.

\subsection{Drought influence on different land-cover types}

Values of pairs $\{\delta \mathrm{NDVI}, \delta \mathrm{NDDI}\}$ and $\left\{\mathrm{NDVI}_{\mathrm{M}}, \mathrm{NDDI}_{\mathrm{M}}\right\}$ were also computed for pixels corresponding to the main land-cover classes and the distribution of the corresponding centroids was analysed for the two fire seasons of 2003 and 2005 (Fig. 6).

As in Fig. 5, results for 2003 refer to the surrounding of burnt areas (Fig. 6, left panel) and to all the considered burnt scars of 2005 (Fig. 6, right panel), the main difference being that burnt areas are now grouped according to the predominant four major land-cover types. Concerning the pair $\left\{\mathrm{NDVI}_{\mathrm{M}}, \mathrm{NDDI}_{\mathrm{M}}\right\}$ two contrasting features may be observed in the two fire seasons, namely the high level of dryness (as indicated by $\mathrm{NDDI}_{\mathrm{M}}$ ) for all land-covers in the vicinity of burn scars in the 2003 fire season (Fig. 6, top left panel) and the high density of green vegetation (as obtained by $\mathrm{NDVI}_{\mathrm{M}}$ ) over the burnt scars of 2005 fire season (Fig. 6, top right panel). In both fire seasons, the driest land-cover types correspond to shrubland and needle-leaved with the 2005 fire season presenting higher availability of biomass, although not particularly dry. Moreover, broad-leaved forests are generally
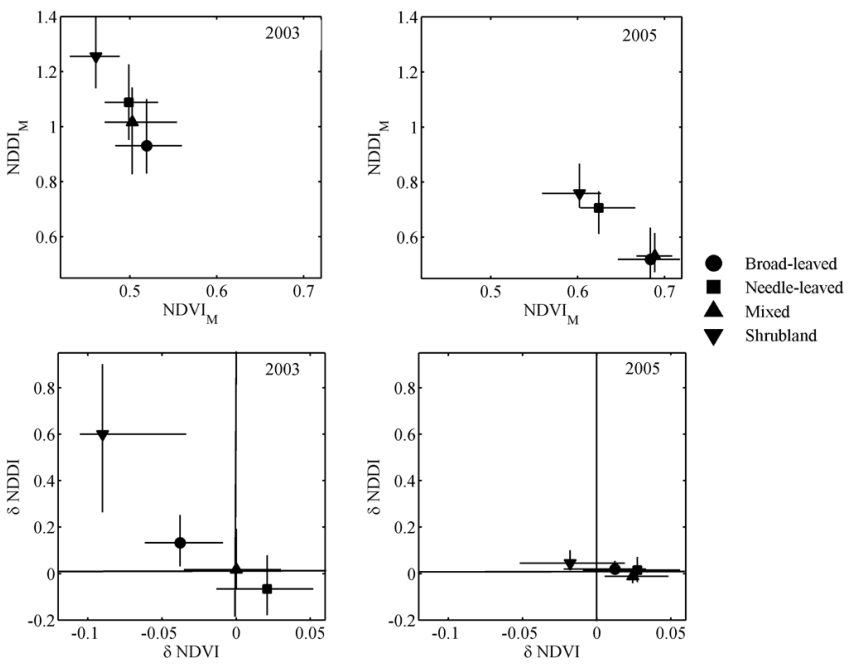

Fig. 6. Dispersion diagrams of centroids corresponding to the pairs $\left\{\mathrm{NDVI}_{\mathrm{M}}, \mathrm{NDDI}_{\mathrm{M}}\right\}$ (top panel) and $\{\delta \mathrm{NDVI}, \delta \mathrm{NDDI}\}$ (bottom panel), for all burnt pixels in the vicinity of burnt scars from 2003 (left panel) and the burnt scars from 2005 (right panel) fire seasons, for each of the main land-cover classes, according to the legend. Coordinates of the centroids are identified by filled circles in the dispersion diagrams, whereas horizontal and vertical bars indicate the interquartile ranges.

the land-cover type less affected by drought, presenting the lowest values of $\mathrm{NDDI}_{\mathrm{M}}$ (Fig. 6 top panel).

The evolution in dryness $\{\delta \mathrm{NDDI}\}$ and vegetation density $\{\delta \mathrm{NDVI}\}$ between late winter and early summer is remarkably different for the 2003 and 2005 fire scars (Fig. 6 bottom panels). Thus, it is worth noting the higher variability of the $\{\delta \mathrm{NDVI}, \delta \mathrm{NDDI}\}$ values for land-cover in the vicinity of burnt areas of 2003 fire season, namely in the case of shrubland that presents the highest (lowest) value of $\delta$ NDDI $(\delta \mathrm{NDVI})$, which indicates a marked increase (decrease) of dryness (vegetation) from late winter to summer. In general, shrubland and broad-leaved present a marked difference between late winter and early summer, with a large decrease in NDVI from late winter to summer and an increase in NDDI (Fig. 6, left bottom panel), corresponding to lower photosynthetic activity and lower moisture content. On the other hand, $\delta$ NDDI values for all land-covers over burnt scars of the 2005 fire season reveal lower variability and lower absolute values, as mentioned above (Fig. 6, right bottom panel). In fact, the decrease in vegetation density is not so evident for 2005 burnt scars, namely in shrubland, as for 2003 burnt scars. Nevertheless, in both years, the decrease in NDVI and increase in NDDI from late winter/spring to summer are well apparent for shrubland, given the low negative values of $\delta$ NDVI and high positive ones of $\delta$ NDDI of the corresponding centroid, being particularly more evident for the 2003 fire season.

Furthermore, the general differences between land-cover types are worth being stressed, as shrubland is the one with higher sensibility to dryness, whereas broad-leaved forests 
present lower level of dryness, as suggested by the low values of $\mathrm{NDDI}_{\mathrm{M}}$. In fact, Mediterranean broad-leaved forests are well adapted to hot and dry summer seasons, since broadleaved species developed plant traits such as long roots that allow them to capture water at deeper levels below ground (Barboni et al., 2004). Nevertheless, the dry conditions over a short period from late winter to summer in 2003 lead to a decrease of broad-leaved greenness and density, as suggested by the negative values of $\delta$ NDVI. Despite the higher level of dryness over coniferous forest in the 5 months before summer season (as indicated by $\mathrm{NDDI}_{\mathrm{M}}$ ), it should be noted that $\delta$ NDVI values do not reveal a decrease in greenness or vegetation density from late winter/spring to summer. These features confirm that coniferous forests are more resistant to short-term droughts than broad-leaved forest (Allen et al., 2010).

Finally, it is worth stressing that results obtained confirm the usefulness of NDDI to the evaluate dryness of vegetation especially in summer months (Gu et al., 2007), as it incorporates information on photosynthetic activity and water availability for live vegetation. In particular, its simultaneous usage with $\delta$ NDVI, allows understanding the corresponding impact on vegetation greenness and density, leading to a more detailed picture of the ability of the different land-cover types to cope with short-term dry conditions.

\section{Drought impact on post-fire vegetation recovery for 2003 fire season}

As already shown, the exceptional water-stress conditions during drought over IP had a strong impact on vegetation dynamics, and may therefore have affected post-fire vegetation recovery.

Following Gouveia et al. (2010), the effect of drought on post-fire vegetation recovery was evaluated based on estimations of the so-called lack of greenness, $y$, which is simply defined as a departure of observed NDVI from an ideally healthy state of vegetation. As described in Gouveia et al. (2010) and in Bastos et al. (2011), the temporal evolution of lack of greenness after a fire event may be characterised by means of a mono-parametric model which allows assessing recovery time. In the present study, the effect of drought on times of post-fire vegetation recovery was assessed by setting the values of $y$ during the months of drought as missing data. In fact, Bastos et al. (2011) have shown that a partial removal of values of $y$ from the time series does not affect the estimations of recovery times unless the recovery process is disrupted. In the present study, removal of values of $y$ during drought is a simple way of generating an artificial time series of pixels that were not affected by drought, and whose impact may therefore be assessed by comparing the times of vegetation recovery as estimated by the mono-parametric model with and without missing data, i.e. with and without the effects of drought.
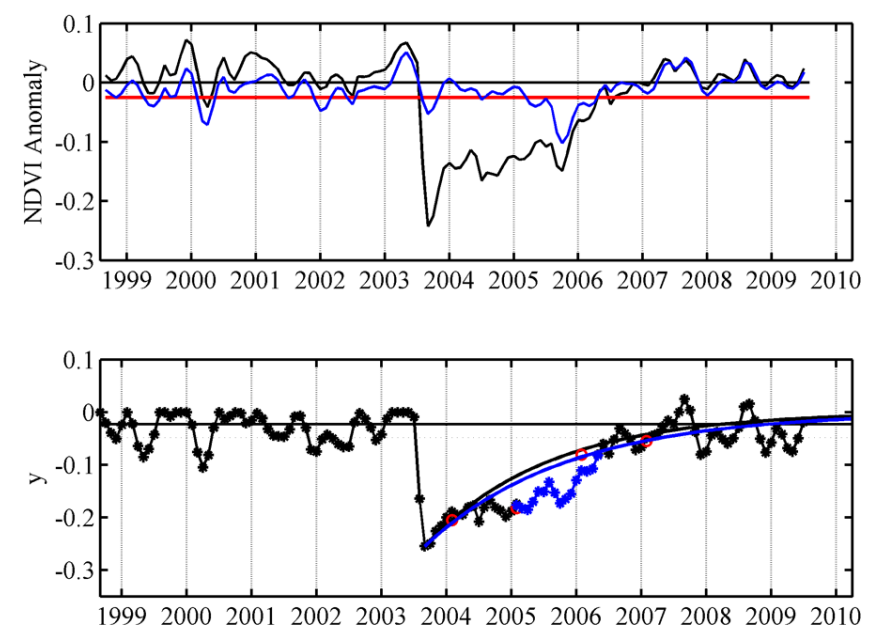

Fig. 7. Monthly NDVI anomaly time series (top) averaged over burn pixels in A3, (black line), and over the corresponding control area (blue line). The red line indicates the NDVI anomaly threshold of -0.025 . The horizontal solid line represents the mean value of $y$ during the pre-fire period and the dashed line (bottom panel) the level of vegetation recovery defined as $90 \%$ of mean. Time series of $y$ in bottom panel shows observed values using the original dataset (black line with asterisks) and values corresponding to the drought period (blue line with asterisks). Modelled recovery using the original dataset (black curve) and setting values corresponding to the drought period as no-value data (blue curve).

It should be noted that, following our previous works (Gouveia et al., 2010; Bastos et al., 2011), we use a definition of vegetation recovery that refers strictly to the reestablishment of pre-fire chlorophyll levels, or pre-fire vegetation density (vegetation greenness). The term "vegetation recovery" does not therefore refer to ecosystems' diversity recovery or to individual tree or species development (that tend to require considerable more months). As before, drought was defined as the period of 9 or more months with negative monthly anomalies of the lack-of-greenness below -0.025 , averaged over a non-burnt control area surrounding each fire scar. Monthly anomalies were averaged over burned areas and unburned control areas all relative to the 2003 fire season. In case of A3, which is represented in Fig. 7, it corresponds to 367 burnt pixels and 887 control pixels. The drought period that affected A3 may be identified by the set of points marked in blue in the time series of lack-ofgreenness, $y$, which correspond to the 14 months with NDVI anomaly lower than -0.025 in the control area; as already mentioned, the impact of drought was assessed by setting these points as missing data in the time series of $y$.

Drought length varied among selected areas, having lasted 14 months in A1 and A3, 10 months in A2, and 16 months in A4 (Table 1). Table 1 summarises the results obtained with the application of the model without considering drought and after excluding the drought period. For A3 and A4, recovery times estimated with removal of drought months from the 
Table 1. Vegetation recovery time $\left(t_{\mathrm{R}}\right)$ and respective $95 \%$ confidence interval $\left(I_{95}\right)$, as estimated by the mono-parametric vegetation recovery model for the burnt scars in 2003. Period corresponding to drought as estimated by the analysis of NDVI anomaly on the surrounding area of each scar. Vegetation recovery time $\left(t_{\mathrm{R}}^{\prime}\right)$ and $95 \%$ confidence interval $\left(I_{95}^{\prime}\right)$, as estimated by the mono-parametric vegetation recovery model after setting the values of $y$ corresponding to the drought period as missing data.

\begin{tabular}{ccccccc}
\hline & \multicolumn{2}{c}{ Original } & & \multicolumn{3}{c}{ Drought correction } \\
\cline { 2 - 3 } \cline { 5 - 7 } & $t_{\mathrm{R}}$ (months) & $I_{95}$ & & Drought months & $t_{\mathrm{R}}^{\prime}$ (months) & $I_{95}^{\prime}$ \\
\hline A1 & 66 & {$[61,71]$} & & 14 & 66 & {$[60,72]$} \\
A2 & 40 & {$[36,46]$} & & 10 & 38 & {$[34,43]$} \\
A3 & 46 & {$[42,50]$} & & 14 & 40 & {$[37,43]$} \\
A4 & 44 & {$[39,52]$} & & 16 & 38 & {$[34,43]$} \\
\hline
\end{tabular}

time series are considerably shorter (up to 6 months) than recovery times estimated with the complete time series. Generally speaking, when data corresponding to drought months are removed, recovery times are considerably shorter and provide a good estimation of the recovery time if the scar was not affected by drought. Burnt area A1 is an exception, but this scar presents a very irregular behaviour from 2007 onwards, with NDVI values oscillating around a stagnation level that is well below the recovery threshold, a behaviour that may be viewed as an indicator of another disturbance, as analysed in Bastos et al. (2011). When setting those suspicious values to missing data, the behaviour is similar to the one in the other three areas, leading to lower recovery times when drought months were removed. This feature may indicate that, at least for this area, there may be an additional factor offsetting the drought effect over vegetation recovery, as the obtained recovery time is markedly longer than in the other burnt scars.

Excluding drought data leads to differences both in estimated recovery times and their corresponding $95 \%$ confidence intervals. It is worth noting that, in the case of A3, the curve for the drought-corrected model (Fig. 7, bottom panel, black line) fits better (with narrower confidence intervals) to the observed $y$ values than the original dataset model (Fig. 7, bottom panel, blue line), especially during the first months after the drought period.

The same procedure was also applied on a pixel by pixel basis in order to assess spatial patterns of differences in estimated recovery times. Figure 8 represents recovery time $\left(t_{\mathrm{R}}\right)$ fields over burn pixels in A3, computed by applying the mono-parametric vegetation recovery model, pixel by pixel, to the original dataset (left panel, OD), to the dataset with values corresponding to the drought period as no-value data (central panel, D), as well as the difference between them, $t_{\mathrm{R}}$ OD $-t_{\mathrm{R}} \mathrm{D}$ (right panel). It is clear that, with exception of a few pixels, the removal of drought values leads to shorter recovery times. Since these differences may be associated to differences in land-cover type response to drought, results for the two main land-cover classes (needle-leaved evergreen and shrub cover evergreen) were compared to the overall area (Table 2). Needle-leaved forest has been under vegetative
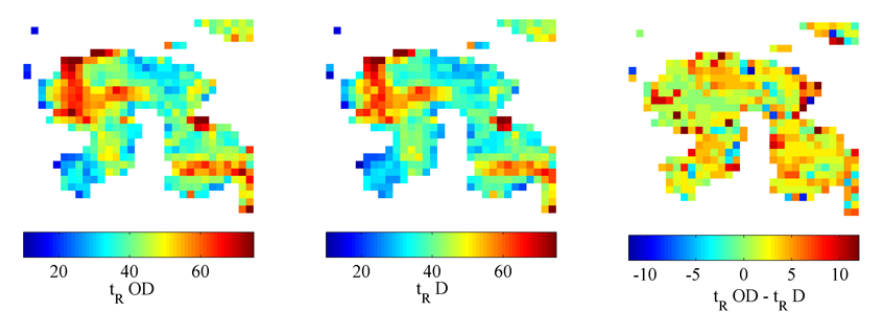

Fig. 8. Recovery time $\left(t_{\mathrm{R}}\right)$ fields over burn pixels in A3, computed by applying the mono-parametric vegetation recovery model, pixel by pixel, to the original dataset (left panel, OD), to the dataset with values corresponding to the drought period as no-value data (central panel, D) and the difference between recovery time fields (right panel).

stress for a period considerably longer (28 months) than both shrubland and the overall area (14 months). This feature could be related to the progressive decrease of soil moisture since the beginning of 2004, associated with the previous minor drought that affected IP (Garcia-Herrera et al., 2007). Furthermore, these results are in good agreement with previous works which showed that needle-leaved growth decreases and mortality increases in response to long-term dry conditions (Allen et al., 2010). Moreover, when comparing results obtained based on the original and the drought corrected datasets, needle-leaved forest presents a markedly higher decrease (from 43 to 35 months) than the one observed with shrubland (that is just from 39 to 38 months). This fact may be explained by the different plant recovery traits that characterise each land-cover type. Coniferous in this region are composed essentially of Maritime Pine ( $\mathrm{Pi}$ nus pinaster) whose regeneration relies on seedlings that require water to develop, whereas shrubland is composed by a larger diversity of species, some of which are resprouters that have established roots that increase their resistance to drought. Setting the values corresponding to the drought period as missing values leads to different results in those landcover types whose regeneration is considerably affected by water-stress conditions, but seems to have little or no effect in those less sensitive to drought, such as evergreen shrubland (Table 2). 
Table 2. As in Table 1 but with regard to A3, values computed for all pixels and for each of the two main land-cover types, according to GLC2000.

\begin{tabular}{lccccccc}
\hline & \multicolumn{2}{c}{ Original } & & \multicolumn{3}{c}{ Drought correction } \\
\cline { 2 - 3 } \cline { 6 - 7 } & $t_{\mathrm{R}}$ (months) & $I_{95}$ & & Drought months & $t_{\mathrm{R}}^{\prime}$ (months) & $I_{95}^{\prime}$ \\
\hline Overall & 46 & {$[42,50]$} & & 14 & 40 & {$[37,43]$} \\
Needle-leaved, evergreen & 43 & {$[38,48]$} & & 28 & 35 & {$[31,40]$} \\
Shrubland, evergreen & 39 & {$[35,44]$} & & 14 & 38 & {$[34,42]$} \\
\hline
\end{tabular}
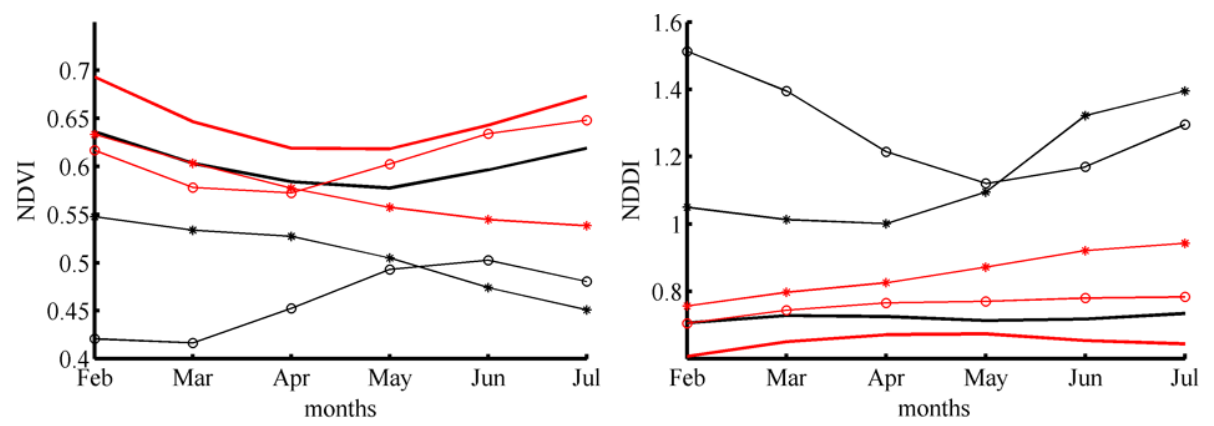

Fig. 9. Monthly values of NDVI (left panel) and NDDI (right panel) for the period of February to July 2005 averaged over all the considered 2005 burnt scars (solid line), over A5 (circles) and over A6 (star), for burned (red) and unburned (black) pixels.

The extreme water-stress conditions to which vegetation is subject during drought events appear, in general, to delay the regeneration process, which is to be expected since water availability is determinant to photosynthesis and, as shown in (Gouveia et al., 2009) this drought was contemporaneous with the period of high photosynthetic activity.

\section{Drought impact on pre-fire vegetation for 2005 fire season}

In order to assess the impact of the 2004/2005 drought on vegetation that burned in the following fire season, $\delta$ NDVI, $\delta$ NDDI, fire damage and recovery time fields were calculated for each of the selected scars from 2005, i.e. A5 to A12. Following Bastos et al. (2011), fire damage is defined as the normalised difference of NDVI values (NDVI DIFF$_{\text {) before and }}$ after the fire event, both evaluated in May, and can be considered as a measure of the impact of fire on the new phenological cycle.

\subsection{Difference in NDVI and NDDI distributions for burned and unburned sets of pixels}

The distributions of NDVI and NDDI were analysed over the scars of 2005 and over the area surrounding the scars, in order to evaluate whether burned and unburned pixels presented differences in their response to drought over late winter, spring and early summer months before the fire (Fig. 9). Comparison of the behaviour of burned and unburned pixels averaged over all the considered 2005 burnt scars (solid lines) reveals marked differences between both types, with the former presenting higher values of NDVI and lower values of NDDI than those observed in the latter. Although the difference between burned and unburned pixels is kept constant throughout the year for NDVI, the difference in NDDI values is higher in late winter and early summer. This is mainly due to the lower values of NDDI for burned pixels observed during these seasons, which indicates that vegetation had higher levels of moisture availability. On the other hand, the overall higher values of NDVI observed for burnt pixels indicate higher availability of green vegetation when compared with non-burnt pixels located nearby, which present lower vegetation density of green vegetation. This is particularly clear when analysing burnt scars, such as A5 and A6, that are the most affected by dryness (i.e. with higher values of $\mathrm{NDDI}_{\mathrm{M}}$ ) (Fig. 9), although in the remaining areas, lower values of NDVI and higher ones of NDDI, are consistently observed over the area surrounding the scar. Furthermore, these two burned scars present different responses to dry conditions. While, in the case of A6, NDVI decreases and NDDI increases continuously from late winter to early summer in burnt pixels, there is, in A5, an increase in NDVI values from late winter to early summer along with a decrease in NDDI in spring. These distinct behaviours could be associated with differences in phenology, with A5 presenting a phenological cycle that has a maximum during late summer, as well as with the distinct phases of the phenological cycle at which drought affected vegetation in each scar.

Results suggest that burned areas were characterized by higher amounts of available fuel and leaf moisture content 

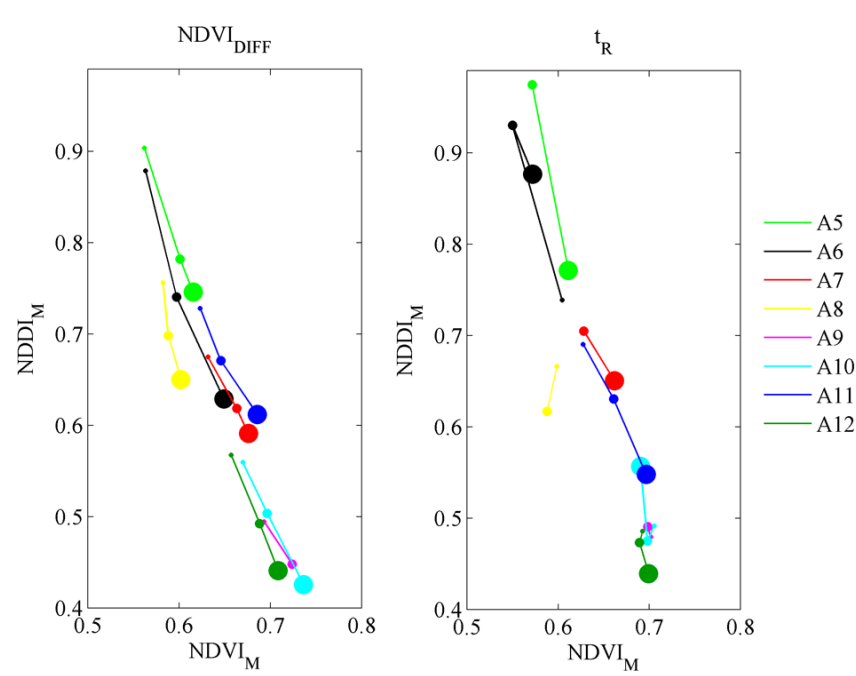

Fig. 10. Centroids of $\left\{\mathrm{NDVI}_{\mathrm{M}}, \mathrm{NDDI}_{\mathrm{M}}\right\}$ respecting to each class of fire damage (NDVI $I_{\text {DIFF }}$, left panel) and recovery time $\left(t_{\mathrm{R}}\right.$-right panel) for selected burnt scars from 2005. Size of markers indicates low, intermediate and high classes of fire damage and recovery times. Coordinates of the centroids are identified by filled circles in the dispersion diagrams.

over the months preceding the fire event, while unburned areas correspond to those pixels where vegetation was under relatively higher vegetative and water stress over the first half of year. On the other hand, the fact that unburned pixels presented markedly low values of leaf moisture content (high NDDI) during spring and summer is associated to lower levels of photosynthetic activity (low NDVI), i.e. low biomass production and, thus, less available fuel.

Finally, it is worth noting that despite presenting lower values of NDDI than the surroundings, burnt pixels are characterized by NDDI values above 0.5 and may be, considered to be relatively dry. Accordingly, results suggest a certain level of fire selectivity for pixels presenting lower vegetative and water stress over spring and early summer, which emphasises the importance of fuel availability in fire occurrence over the Iberian Peninsula (Pausas and Fernández-Muñoz, 2011; Pausas and Paula, 2012).

\subsection{Pre-fire conditions, fire damage and recovery time}

In order to evaluate whether pre-fire conditions influenced the level of fire damage (NDVI DIFF$_{\text {) }}$ ) or the time of post-fire recovery $\left(t_{R}\right)$, three classes of NDVI $I_{\text {DIFF }}$ and $t_{\mathrm{R}}$ were defined based on the terciles of each variable for every pixel of all the selected scars. Centroids of pairs $\left\{\mathrm{NDVI}_{\mathrm{M}}, \mathrm{NDDI}_{\mathrm{M}}\right\}$ were accordingly computed for each scar from 2005 and considering each class of NDVI $I_{\text {DIFF }}$ and $t_{R}$, as shown in Fig. 10; size of markers (small, medium or large) indicates the respective

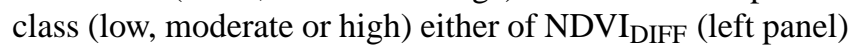
or of $t_{\mathrm{R}}$ (right panel), whereas colours identify selected scars.
Observation of dispersion diagrams (Fig. 10) for the three

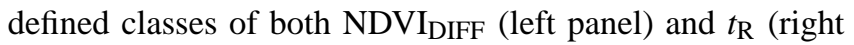
panel) suggests that centroids tend to be located along a narrow diagonal band ranging from low (high) values of $\mathrm{NDVI}_{M}\left(\mathrm{NDDI}_{M}\right)$ to high (low) values of $\mathrm{NDVI}_{M}\left(\mathrm{NDDI}_{M}\right)$. In particular, it may be observed that, for each scar, centroids associated either to the class of most severe fire damage $\left(\mathrm{NDVI}_{\mathrm{DIFF}}\right)$ are characterized by the higher values of $\mathrm{NDVI}_{M}$ (i.e. greener/denser vegetation) and lower values of $\mathrm{NDDI}_{M}$ (i.e. vegetation less affected by dry conditions). This feature is also present for the corresponding recovery time $\left(t_{\mathrm{R}}\right)$ centroids, with the exceptions of scars A6 and A10. These results are especially interesting since they suggest that pixels associated to dense and unstressed vegetation are more prone to higher fire damage and longer times of recovery; for instance, for values of $\mathrm{NDDI}_{\mathrm{M}}$ above 0.75 there are no centroids associated to the highest class of fire damage (Fig. 10, left panel).

As shown in Table 3, for each scar, as well as for the main land-cover types in each scar, the relationship of NDVI $I_{\text {DIFF }}$ with both $\mathrm{NDVI}_{M}$ and $\mathrm{NDDI}_{M}$ was assessed by evaluating the respective correlation coefficients between variables (values statistically significant at the $5 \%$ level are highlighted in bold). Other land-cover types within each scar were not analysed due to the lack of a sufficient number of points.

In general, a positive relationship between $\mathrm{NDVI}_{\text {DIFF }}$ and $\mathrm{NDVI}_{\mathrm{M}}$ is observed, being stronger in those areas with higher green vegetation density (A9, A10 and A12) or in areas with less water content (A6). A significant negative relationship between NDVI $\mathrm{DIFF}_{\text {and }} \mathrm{NDDI}_{\mathrm{M}}$ may be also observed for all regions, being again stronger in areas presenting higher fuel availability (A9, A10, A12). In the case of A6 (area with less water content, see Fig. 5) and A10 (area with higher biomass, see Fig. 5), dispersion diagrams (Fig. 11, left panels) of the pairs $\left\{\mathrm{NDVI}_{\mathrm{DIFF}}, \mathrm{NDVI}_{\mathrm{M}}\right\}$ and $\left\{\mathrm{NDVI}_{\mathrm{DIFF}}, \mathrm{NDDI}_{\mathrm{M}}\right\}$ clearly show a monotonic positive relationship between $\left\{\mathrm{NDVI}_{\mathrm{DIFF}}\right.$, $\left.\mathrm{NDVI}_{\mathrm{M}}\right\}$ and a negative relationship (Fig. 11, right panels) between $\left\{\mathrm{NDVI}_{\mathrm{DIFF}}, \mathrm{NDDI}_{\mathrm{M}}\right\}$. In the case of A6 (top panel) and A10 (bottom panel), the best fit of the linear adjustment is observed for $\left\{\mathrm{NDVI}_{\mathrm{DIFF}}, \mathrm{NDVI}_{\mathrm{M}}\right\}$, especially for A10 where it explains almost $60 \%$ of the variance. Furthermore, in the case of the latter burnt scar, the linear adjustment also provides a good fit for $\left\{\mathrm{NDVI}_{\mathrm{DIFF}}, \mathrm{NDDI}_{\mathrm{M}}\right\}$, explaining almost $50 \%$ of the variance. The differences between the two burnt scars may be due to the relative composition of each land-cover, as both areas are largely covered by needleleaved but A6 presents high coverage of shrubland and A10 of mixed forests.

The evaluation of the influence of land-cover composition in this analysis reveals marked differences between certain land-cover types (Table 3). The case of A7 is worth being noted since despite presenting overall low correlation values between fire damage and $\mathrm{NDVI}_{\mathrm{M}}$ or $\mathrm{NDDI}_{\mathrm{M}}$, broad-leaved forests present very high correlations of 0.90 for $\left\{\mathrm{NDVI}_{\mathrm{DIFF}}\right.$, $\left.\mathrm{NDVI}_{\mathrm{M}}\right\}$ and -0.86 for $\left\{\mathrm{NDVI}_{\mathrm{DIFF}}, \mathrm{NDDI}_{\mathrm{M}}\right\}$, which are the 
Table 3. Correlation coefficients between $\mathrm{NDVI}_{\mathrm{DIFF}}, t_{\mathrm{R}}$ and $\mathrm{NDVI}_{\mathrm{M}}, \mathrm{NDDI}_{\mathrm{M}}$. Bold numbers correspond to statistically significant values at $5 \%$ level.

\begin{tabular}{|c|c|c|c|c|c|c|c|c|}
\hline & A5 & A6 & A7 & A8 & A9 & A10 & A11 & A12 \\
\hline $\mathrm{NDVI}_{\text {DIFF }}, \mathrm{NDVI}_{\mathrm{M}}$ & 0.63 & 0.71 & 0.46 & 0.46 & 0.68 & 0.74 & 0.63 & 0.65 \\
\hline Broad deciduous & - & - & 0.90 & - & 0.65 & - & - & 0.70 \\
\hline Needle-leaved evergreen & 0.61 & 0.63 & 0.43 & 0.54 & - & 0.73 & 0.59 & - \\
\hline Shrubland deciduous & - & - & - & 0.09 & - & - & - & - \\
\hline Shrubland evergreen & - & 0.62 & - & - & - & - & 0.42 & - \\
\hline Mixed & - & - & - & - & 0.62 & 0.75 & - & 0.65 \\
\hline $\mathrm{NDVI}_{\text {DIFF }}, \mathrm{NDDI}_{\mathrm{M}}$ & -0.45 & -0.56 & -0.55 & -0.61 & -0.61 & -0.68 & -0.48 & -0.72 \\
\hline Broad deciduous & - & - & -0.86 & - & -0.54 & - & - & -0.78 \\
\hline Needle-leaved evergreen & -0.41 & -0.52 & -0.66 & -0.60 & - & $-\mathbf{0 . 7 0}$ & -0.52 & - \\
\hline Shrubland deciduous & - & - & - & -0.10 & - & - & - & - \\
\hline Shrubland evergreen & - & -0.28 & - & - & - & - & 0.02 & - \\
\hline Mixed & - & - & - & - & -0.63 & -0.65 & - & -0.69 \\
\hline$t_{\mathrm{R}}$ vs. NDVI $\mathrm{DIFF}_{\mathrm{DIF}}$ & 0.49 & 0.70 & 0.07 & 0.23 & -0.30 & -0.04 & 0.45 & 0.41 \\
\hline
\end{tabular}
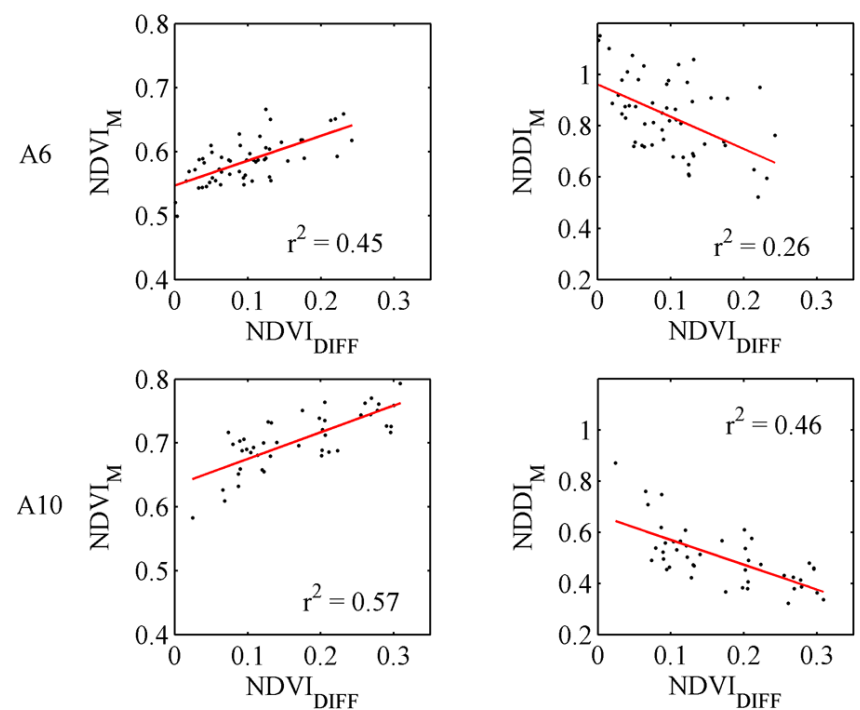

Fig. 11. Dispersion diagrams of the pairs $\left\{\mathrm{NDVI}_{\mathrm{DIFF}}, \mathrm{NDVI}_{\mathrm{M}}\right\}$ (left panel) and $\left\{\mathrm{NDVI}_{\mathrm{DIFF}}, \mathrm{NDDI}_{\mathrm{M}}\right\}$ (right panel) for pixels corresponding to forests and shrubland for A6 (top panel) and A10 (bottom panel).

highest correlations observed for all cases. Needle-leaved forest, which presents the strongest correlation between the variables for the area with higher biomass (A10), generally present a positive correlation for pairs NDVI $_{\text {DIFF }}$, $\left.\mathrm{NDVI}_{\mathrm{M}}\right\}$ (between 0.43 to 0.73 ) and negative correlations for pairs $\left\{\mathrm{NDVI}_{\mathrm{DIFF}}, \mathrm{NDDI}_{\mathrm{M}}\right\}$ (spanning from -0.41 to -0.70 ). The other land-cover types follow a similar behaviour, with positive correlations being obtained for pairs $\left\{\mathrm{NDVI}_{\mathrm{DIFF}}\right.$, $\left.\mathrm{NDVI}_{\mathrm{M}}\right\}$ and negative correlations for pairs $\left\{\mathrm{NDVI}_{\mathrm{DIFF}}\right.$, $\mathrm{NDDI}_{\mathrm{M}}$, although in the case of shrubland, only the correlation between $\left\{\mathrm{NDVI}_{\mathrm{DIFF}}, \mathrm{NDVI}_{\mathrm{M}}\right\}$ is significant, for evergreen shrubland pixels.
Fire damage appears, therefore, to be significantly determined by both vegetation density and water-stress conditions before fire occurrence (given by $\mathrm{NDVI}_{\mathrm{M}}$ ). Fire damage tends to be higher in the presence of higher vegetation density before fire and lower when vegetation presents high water deficits (given by $\mathrm{NDDI}_{M}$ ) during the months that precede the fire. This may be related to the fact that vegetation subject to high levels of water-stress during spring and early summer may not be able to attain regular growth or may even be subject to increased mortality rates (Catry et al., 2010). Fire damage is, thus, mainly driven by fuel availability, which in turn has been shown previously to be determined by vegetation dynamics over spring and summer before the fire season.

Although the relationship between $t_{\mathrm{R}}$ classes and NDVI and NDDI values is not as clear, longer recovery times appear to be associated to higher levels of NDVI, although a weaker relationship is observed in some cases, for instance in A7.

\section{Discussion and concluding remarks}

Mediterranean ecosystems are frequently subject to severe disturbances such as droughts and wildfires which may occur simultaneously. Since vegetation behaviour in Mediterranean ecosystems is limited by water availability, understanding the combined effects of drought both in the onsetting of the following fire season and in the dynamics of post-fire vegetation recovery becomes particularly relevant. Relying on NDVI, NDWI and NDDI data, as obtained from the VEGETATION dataset, the present work aimed at assessing the influence of the 2004/2005 drought that affected the whole IP on vegetation recovery following the outstanding 2003 fire season and in pre-fire vegetation dynamics, regarding the fire season of 2005.

Drought severity was assessed by means of the cumulative negative effect on photosynthetic activity (NDVI) and 
vegetation dryness (NDDI) over the hydrological year. Analysis of NDVI and NDDI anomalies over 2005 indicates that roughly two-thirds of IP presented vegetative stress and low water availability conditions during spring and early summer. Values of $\mathrm{NDDI}_{\mathrm{M}}$ that were obtained for the areas surrounding the 2003 burn scars are higher than those for the burn scars of 2005, whereas the corresponding values of $\mathrm{NDVI}_{\mathrm{M}}$ are significantly lower. This implies that the 2005 burned scars correspond to a distinct setting with higher available biomass and higher leaf moisture. It is also worth stressing the general differences that may be observed between landcover types, where shrubland is the one presenting higher levels of dryness, whereas broad-leaved forests present lower water stress, as indicated by the low values of $\mathrm{NDDI}_{\mathrm{M}}$. The analysis of the intra-annual change in vegetation greenness and density, as obtained by $\delta$ NDVI values, further confirms that coniferous forests are more resistant to short-term droughts than broad-leaved forests (Allen et al., 2010). NDDI has therefore shown to be particularly useful to evaluate the dry conditions of vegetation especially in the summer months (Gu et al., 2007), as it combines information on photosynthetic activity and leaf moisture content. The combined usage of $\delta \mathrm{NDVI}$, allows understanding drought impact on vegetation greenness and density, leading to a more detailed picture of the ability of the different land-cover types to cope with short-term dry conditions.

The analysis of drought influence on post-fire recovery times of 2003 burned scars reveals that water-stress conditions during drought events led to a decrease in recovery rates, delaying the regeneration process. This is due to the crucial role of water on photosynthetic activity in Mediterranean ecosystems, which also explains differences observed when assessing the impact of drought on recovery for distinct land-cover types, the recovery time of coniferous forests being particularly affected by drought due to the fact that coniferous rely on post-fire seedling germination, while others resprout from live biomass with established root systems.

The analysis of drought impact on pre-fire vegetation conditions in 2005 revealed fire selectivity for pixels presenting lower vegetative and water-stress conditions during spring and early summer, emphasizing the role of fuel availability in fire occurrence over IP. Moreover, vegetation dynamics over the months preceding the fire, in particular the fuel load, has shown to significantly influence the levels of fire damage. Finally, vegetation dynamics over the year preceding the fire appears to influence less markedly post-fire recovery times, but this analysis would require further development since recovery time depends on a large variety of factors, including fire damage.
Acknowledgements. This work was partly supported by the EU 7th Framework Program (FUME) contract number 243888 and by Portuguese Science Foundation (FCT) through project FLAIR (PTDC/AAC-AMB/104702/2008). Ana Bastos was funded by Portuguese Science Foundation (SFRH/BD/78068/2011). NDVI, B0, B2 and B3 datasets were kindly supplied by VITO (http://free.vgt.vito.be) and the land cover thematic map was extracted from the Global Landcover Project (GLC2000).

Edited by: C. Andrade

Reviewed by: M. Lazzari and one anonymous referee

\section{References}

Allen, C. D., Macalady, A. K., Chenchouni, H., Bachelet, D., McDowell, N., Vennetier, M, Kitzberger, T., Rigling, A., Breshears, D. D., Hogg, E. H. Gonzalez, P., Fensham, R., Zhang, Z., Castro, J., Demidova, N., Lim, J.H., Allard, G., Running, S. W., Semerci, A., and Cobb, N.: A global overview of drought and heat-induced tree mortality reveals emerging climate change risks for forests, Forest Ecology and Management, 259, 660-684, 2010.

Anderson, L. O., Mahli, Y., Aragão, L. E. O. C., Ladle, R., Arai, E., Barbier, N., and Phillips, O.: Remote sensing detection of droughts in Amazonian forest canopies, New Phytol., 187, 733750, 2010.

Barboni, D., Harrison, S. P., Bartlein, P. J., Jalut, G., New, M., Prentice, I. C., Sanches-Goni, M.-F., Spessa, A., Davis, B., and Stevenson, A. C.: Relationships between plant traits and climate in the Mediterranean region: A pollen data analysis, J. Vegetation Sci., 15, 635-646, 2004.

Bastos, A., Gouveia, C. M., DaCamara, C. C., and Trigo, R. M.: Modelling post-fire vegetation recovery in Portugal, Biogeosciences, 8, 3593-3607, doi:10.5194/bg-8-3593-2011, 2011.

Catry, F. X., Rego, F., Moreira, F., Fernandes, P. M., and Pausas, J. G.: Post-fire tree mortality in mixed forests of central Portugal, Forest Ecol. Manage., 260, 1184-1192, 2010.

Ceccato, P., Flasse, S., Tarantola, S., Jacquemoud, S., and Grégoire, J. M.: Detecting vegetation leaf water content using reflectance in the optical domain, Remote Sens. Environ., 77, 22-33, 2001.

Chuvieco, E., Aguado, I., Yebra, M., Nieto, H., Salas, J., Martín, M. P., Vilar, L., Martínez, J., Martín, S., Ibarra, P., de la Riva, J., Baeza, J., Rodríguez F., Molina, J. R., Herrera, M. A., and Zamora, R.: Development of a Framework for fire risk assessment using remote sensing and geographic information system Technologies, Ecol. Model., 221, 46-58, 2010.

De Luís, M., García-Cano, M. F., Cortina, J., Raventós, J., González-Hidalgo, J. C., and Sánchez, J. R.: Climatic trends, disturbances and short-term vegetation dynamics in a Mediterranean shrubland, Forest Ecol. Manage., 147, 25-37, 2001.

De Santis, A. and Chuvieco, E.: Burn severity estimulation from remotely sensed data: Performance of simulation versus empirical models, Remote Sens. Environ., 108, 422-435, 2007.

Díaz-Delgado, R. and Pons, X.: Spatial patterns of forest fires in Catalonia (NE of Spain) along the period 1975-1995, Analysis of vegetation recovery after fire, Forest Ecol. Manage., 147, 6774, 2001.

Díaz-Delgado, R., Salvador, R., and Pons, X.: Monitoring of plant community regeneration after fire by remote sensing, in: Fire 
management and landscape ecology, edited by: Traboud, L., Int. Association of Wildland Fire, Fairfield, WA, 315-324, 1998.

Fox, D. M., Maselli, F., and Carrega, P.: Using SPOT images and field sampling to map burn severity and vegetation factors affecting post forest fire erosion risk, Catena, Elsevier, 75, 326-335, 2008.

Gao, B. C.: NDWI A Normalized Difference Water Index for Remote Sensing of Vegetation Liquid Water From Space, Remote Sens. Environ., 58, 257-266, 1996.

Garcia-Herrera, R., Paredes, D., Trigo, R. M., Trigo, I. F., Hernández, E., Barriopedro, D., and Mendes, M. A.: The Outstanding 2004/05 Drought in the Iberian Peninsula: Associated Atmospheric Circulation, J. Hydrometeorol., 8, 483-498, 2007.

Gond, V., Bartholomé, E., Ouattara, F., Nonguierma, A., and Bado, L.: Surveillance et cartographie des plans d'eau et des zones humides et inondables en régions arides avec l'instrument VEGETATION embarqué sur SPOT-4, Int. J. Remote Sens, 25, 9871004, 2004.

Gouveia, C., Trigo, R. M., DaCamara, C. C., Libonati, R., and Pereira, J. M.: The North Atlantic Oscillation and European vegetation dynamics, Int. J. Climatol., 14, 1835-1847, 2008.

Gouveia, C., Trigo, R. M., and DaCamara, C. C.: Drought and vegetation stress monitoring in Portugal using satellite data, Nat. Hazards Earth Syst. Sci., 9, 185-195, doi:10.5194/nhess-9-1852009, 2009.

Gouveia, C., DaCamara, C. C., and Trigo, R. M.: Post-fire vegetation recovery in Portugal based on spot/vegetation data, Nat. Hazards Earth Syst. Sci., 10, 673-684, doi:10.5194/nhess-10673-2010, 2010.

Gu, Y., Brown, J. F., Verdin, J. P., and Wardlow, B.: A five-year analysis of MODIS NDVI and NDWI for grassland drought assessment over the central Great Plains of the United States, Geophys. Res. Lett., 34, 1-6, 2007.

Hagolle, O., Lobo, A., Maisongrande, P., Duchemin, B., and De Pereira, A.: Quality assessment and improvement of SPOT/VEGETATION level temporally composited products of remotely sensed imagery by combination of VEGETATION 1 and 2 images, Remote Sens. Environ., 94, 172-186, 2005.

Hao, X. and Qu, J.: Retrieval of real-time live fuel moisture content using MODIS measurements, Remote Sens. Environ., 108, 130137, 2007.

Hartigan, J. A. and Wong, M. A.: Algorithm AS 136: A K-Means Clustering Algorithm, J. Roy. Stat. Soc. C-App., 28, 100-108, 1979.

Holben, B. N.: Characteristics of maximum-value composite images from temporal AVHRR data, Int. J. Remote Sens., 7, 14171434, 1986.

JRC-EC: Forest Fires in Europe 2010, Report No. 11, Institute for Environment and Sustainability, European Comission, 2010.

Julien, Y., Sobrino, J. A., and Verhoef, W.: Changes in land surface temperatures and NDVI values over Europe between 1982 and 1999, Remote Sens. Environ., 103, 43-55, 2006.

Levinson, D. H. (Ed.): State of the Climate in 2004, B. Am. Meteorol. Soc., 87, S1-S102, 2005.

Los, S. O.: Linkages between global vegetation and climate: an analysis based on NOAA-Advanced Very High Resolution Radiometer Data, Ph.D. thesis, Vrije Universiteit, Amsterdam, 179 pp., 1998.
MacQueen, J. B.: Some methods for classification and analysis of multivariate observations, Proc. 5th Berkeley Symposium on Mathematical Statistics and Probability 1, University of California Press, 281-297, 1967.

Maisongrande, P., Duchemin, B. and Dedieu, G.: VEGETATION/SPOT - An Operational Mission for the Earth Monitoring: Presentation of New Standard Products, Int. J. Remote Sens., 25, 9-14, 2004.

Maki, M., Ishiahra, M., and Tamura, M.: Estimation of leaf water status to monitor the risk of forest fires by using remotely sensed data, Remote Sens. Environ., 90, 441-450, 2004.

Malkinson, D., Wittenberg, L., Beeri, O., and Barzilai, R.: Effects of repeated fires on the structure, composition, and dynamics of Mediterranean maquis: Short- and long-term perspectives, Ecosystems, 14, 478-488, 2011.

Naveh, Z.: The evolutionary significance of fire in the Mediterranean region, Plant Ecol., 29, 199-208, 1975.

Pausas, J. G. and Fernández-Muñoz, S.: Fire regime changes in the Western Mediterranean Basin: from fuel-limited to drought-driven fire regime, Climatic Change, 110, 215-226, doi:10.1007/s10584-011-0060-6, 2011.

Pausas, J. G. and Paula, S.: Fuel shapes the fire-climate relationship: evidence from Mediterranean ecosystems, Global Ecol. Biogeog., doi:10.1111/j.1466-8238.2012.00769.x, 2012

Pausas, G. J. and Vallejo, V. R.: The role of fire in European Mediterranean Ecosystems, in: Remote sensing of large wildfires in the European Mediterranean basin, edited by: Chuvieco, E., Springer-Verlag, 3-16, 1999.

Pereira, M. G., Trigo, R. M., DaCamara, C. C., Pereira, J. M. C., and Leite, S. M.: Synoptic patterns associated with large summer forest fires in Portugal, Agr. Forest Meteorol., 129, 11-25, doi:10.1016/j.agrformet.2004.12.007, 2005.

Pereira, M. G., Malamud, B. D., Trigo, R. M., and Alves, P. I.: The history and characteristics of the 1980-2005 Portuguese rural fire database, Nat. Hazards Earth Syst. Sci., 11, 3343-3358, doi:10.5194/nhess-11-3343-2011, 2011.

Rahman, H. and Dedieu, G.: SMAC: a simplified method for the atmospheric correction of satellite measurements in the solar spectrum, Int. J. Remote Sens., 15, 123-143, 1994.

Röder, A., Hill, J., Duguy, B., Alloza, J. A., and Vallejo, R.: Using long time series of Landsat data to monitor fire events and postfire dynamics and identify driving factors. A case study in the Ayora region (eastern Spain), Remote Sens. Environ., 112, 259-273, 2008.

Sellers, P. J., Berry, J. A., Collatz, G. J., Field, C. B., and Hall, F.G.: Canopy reflectance, photosynthesis and transpiration, III, A reanalysis using enzyme kinetics-electron transport models of leaf physiology, Remote Sens. Environ., 42, 187-216, 1992.

Sousa, P. M., Trigo, R. M., Aizpurua, P., Nieto, R., Gimeno, L., and Garcia-Herrera, R.: Trends and extremes of drought indices throughout the 20th century in the Mediterranean, Nat. Hazards Earth Syst. Sci., 11, 33-51, doi:10.5194/nhess-11-33-2011, 2011.

Stöckli, R. and Vidale, P. L.: European plant phenology and climate as seen in a 20-year AVHRR land-surface parameter dataset, Int. J. Remote Sens., 25, 3303-3330, 2004.

Tansey, K., Grégoire, J.-M., Defourny, P., Leigh, R., Pekel, J.-F., van Bogaert, E., and Bartholomé, E.: A new, global, multi-annual (2000-2007) burnt area product at $1 \mathrm{~km}$ resolution, Geophys. 
Res. Lett., 35, L01401, doi:10.1029/2007GL031567, 2008.

Trigo, R. M., García-Herrera, R., Díaz, J., Trigo, I. F., and Valente, M. A.: How exceptional was the early August 2003 heatwave in France?, Geophys. Res. Lett., 32, L10701, doi:10.1029/2005GL022410, 2005.

Trigo, R. M., Pereira, J. M. C., Pereira, M. G., Mota, B., Calado, M. T., DaCamara, C. C., and Santo, F. E.: Atmospheric conditions associated with the exceptional fire season of 2003 in Portugal, Int. J. Clim., 26, 1741-1757, 2006.

Vicente-Serrano, S. M.: Spatial and temporal analysis of droughts in the Iberian Peninsula (1910-2000), Hydrol. Sci. J., 51, 83-97, 2006.
Vicente-Serrano, S. M. and Heredia-Laclaustra, A.: NAO influence on NDVI trends in the Iberian Peninsula (1982-2000), Int. J. Remote Sens., 25, 2871-2879, 2004.

Whelan, R. J.: The ecology of fire. New York: Cambridge University Press, 346 pp., 1995.

Wittenberg, L., Malkinson, D., Beer, O., Halutzy, A., and Tesler, N.: Spatial and temporal patterns of vegetation recovery following sequences of forest fires in a Mediterranean landscape, Mt. Carmel Israel, Catena, Elsevier, 71, 76-83, 2007. 